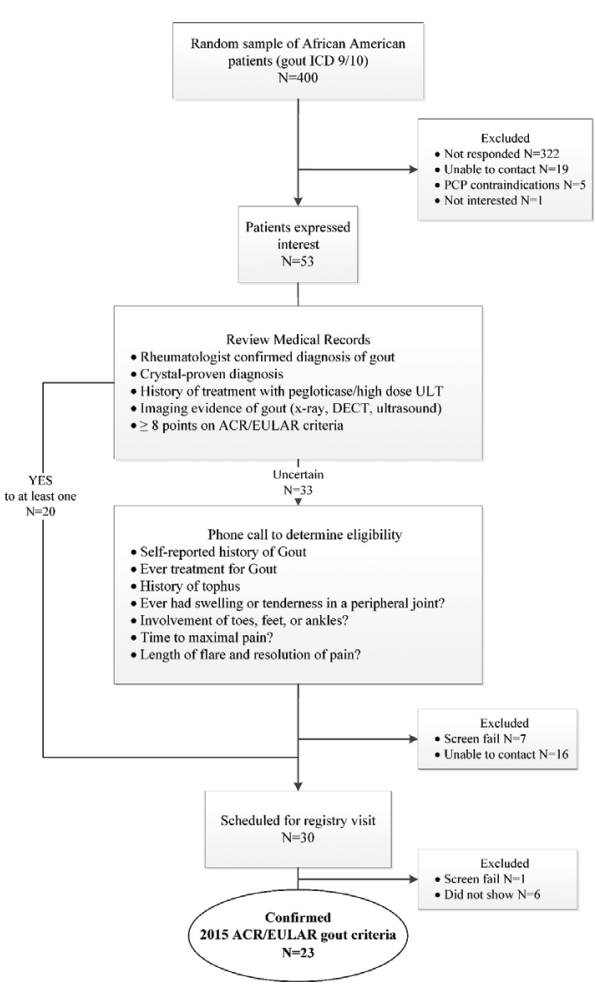

Abstract AB0861 Figure 1. Sequential steps employed to recruit African Americans to gout to a registry

Disclosure of Interests: Giovanni Adami: None declared, Josh Melnick: None declared, Jeff Foster: None declared, Elizabeth Rahn: None declared, Amy Mudano: None declared, Jeffrey Curtis: None declared, Tony Merriman Grant/research support from: Ardeabiosciences, Ironwood Pharmaceuticals, Consultant for: Ardeabiosciences, Ironwood Pharmaceuticals, Lou Bridges: None declared, Kenneth Saag Grant/research support from: Amgen, Ironwood/AstraZeneca, Horizon, SOBI, Takeda, Consultant for: Abbvie, Amgen, Ironwood/AstraZeneca, Bayer, Gilead, Horizon, Kowa, Radius, Roche/Genentech, SOBI, Takeda, Teijin

DOI: 10.1136/annrheumdis-2019-eular.3396

\section{AB0862 EFFICACY AND SAFETY OF US-GUIDED INJECTIONS OF THE KNEES WITH HYALURONIC ACID IN PATIENTS AFFECTED BY OSTEOARTHRITIS ASSOCIATED TO CALCIUM PYROPHOSPHATE DEPOSITION DISEASE: PRELIMINARY RESULTS}

Antonella Adinolfi' ${ }^{1}$, Federica Rumi ${ }^{2}$, Greta Carrara ${ }^{2}$, Marcello Govoni ${ }^{3}$, Bruno Frediani ${ }^{1}$, Carlo Alberto Scirè ${ }^{3}$, Georgios Filippou ${ }^{3} .{ }^{1}$ Unit of Rheumatology, University of Siena, Siena, Italy, ${ }^{2}$ Epidemiology Unit, Italian Society for Rheumatology (SIR), Milano, Italy; ${ }^{3}$ Department of Rheumatology, University of Ferrara, Ferrara, Italy

Background: Calcium pyrophosphate deposition disease (CPPD) and Osteoarthritis $(\mathrm{OA})$ are often associated (1). However, is still controversial how calcium pyrophosphate (CPP) deposits coul d affect OA features (1) and, eventually, the response to the OA treatments.

Objectives: To evaluate the efficacy and the safety of Ultrasound (US)guided injections of the knees with Hyaluronic Acid (HA) in patients with $\mathrm{OA}$ and CPPD, compared to OA.

Methods: Consecutive patients, referred to the outpatient clinic with a clinical and radiological knee $\mathrm{OA}$ required intra-articular (IA) treatment with high molecular weight (HMW) HA and without any clinical inflammatory signs, were enrolled. No limits about OA score [Kellgreen-Lawrence (K-L) score] were used. Patients with diagnosis or suspicion of other chronic inflammatory rheumatic diseases were excluded. For each patients, were recorded age, sex, Body Mass Index (BMI) and K-L score. The presence of CPP deposits were evaluated by US at level of menisci and knee hyaline cartilage, using the OMERACT criteria (2). All the patients were submitted to three IA injections with HA, performed every week. Before each injection, the synovial fluid (SF) was aspirated and its amount recorded. All SF aspiration and injections were US-guided. At baseline and before each injection, the Western Ontario and Mc Master Universities Osteoarthrits Index (WOMAC) was submitted to the patients. The data were analyzed using a Wilcoxon test for independent samples and a regressive logistic model, including age, sex, BMI, K-L, SF and CPPD presence.

Results: We enrolled 23 patients (12 woman [52,17\%]) with a mean age of 67,65 yo $(\mathrm{SD} \pm 11,93)$, a mean $\mathrm{BMI}$ of $27,43(\mathrm{SD} \pm 4,82)$ and a median K-L score of 3 (range 2-3). 10/23 (43,88\%) patients were identified as affected by CPPD at US [6 woman, mean age 67,39 yo $(\mathrm{SD} \pm 12,1)$, BMI $27,14(\mathrm{SD} \pm 4,4)$, median K-L of 3 (range 2,75-3,25)]. No differences about age, BMI and K-L score were observed. Regard the baseline WOMAC, the CPPD group mean $[955,89(\mathrm{SD} \pm 416,5)]$ was significantly higher $(p<0,01)$ than $\mathrm{OA}[379,5(\mathrm{SD} \pm 225,21)]$.

Considering the short term effect, the WOMAC score improved in both groups after the first injection, but it was significantly higher in the CPPD group $(p<0,01)$ and the regressive model analysis, showed that only the CPPD is correlate to the WOMAC change.

After the second injection, the improvement continues but without differences. The regressive model showed that no variables correlate with WOMAC. The data from the long term follow up are not still available. Regarding the SF amount, no differences statistically significant were observed between the two groups at every time.

Conclusion: The US-guided injections with HMWHA at knees appear effective and safe in patients with OA associated to CPPD. Particularly the presence of CPP does not appear a risk factor for the development of inflammation. However, these results are preliminary and should be confirmed in a larger cohort and for a longer follow-up.

\section{REFERENCES}

[1] Abhishek A, et al. Evidence of a systemic predisposition to $C C$ and association between $\mathrm{CC}$ and $\mathrm{OA}$ at distant joints: a cross-sectional study. Arthritis Care Res (Hoboken). 2013 Jul;65(7):1052-8.

[2] Filippou G, et al. Definition and Reliability Assessment of Elementary US Findings in CPPD: A Study by the OMERACT CPPD Ultrasound Subtask Force. J Rheumatol. 2017 Nov;44(11):1744-1749

Disclosure of Interests: Antonella Adinolfi: None declared, Federica Rumi: None declared, Greta Carrara: None declared, Marcello Govoni: None declared, Bruno Frediani: None declared, Carlo Alberto Scirè: None declared, Georgios Filippou Speakers bureau: Laborest, Abbvie, BMS, Sanofi

DOI: 10.1136/annrheumdis-2019-eular.8160

\section{AB0863 AN AUDIT OF MANAGEMENT OF GOUT ACCORDING TO THE BRITISH SOCIETY FOR RHEUMATOLOGY GUIDELINES,2017 IN A TEACHING HOSPITAL RHEUMATOLOGY UNIT}

Siwalik Banerjee, Himashi Anver, Kaushik Chaudhuri. University Hospitals Coventry and Warwickshire, rheumatology, Coventry, United Kingdom

Background: Gout is the most common form of inflammatory arthritis worldwide. Its prevalence is $2.49 \%$ in UK general practice. In spite of the availability of effective treatments in the UK, the incidence of gout has increased in the last decade, the reasons for which are many. There is also evidence that gout is being sub-optimally treated in primary and secondary care. (1)

Fewer than $50 \%$ of patients receive urate lowering therapy (ULT), and many patients on ULT do not achieve the target serum urate level of $300 \mu \mathrm{mol} / /$ or lower. which is essential to prevent further attacks of gout. This target has been proposed by the British Society for Rheumatology (BSR), in the latest guideline from 2017. (2)

Objectives: To asess the compliance of gout management with the BSR 2017 guideline in our unit (a teaching hospital rheumatology department): a) Urate lowering therapy should be discussed with all patients diagnosed with Gout.

b) ULT is strongly advised in patients with recurrent attacks (>2 over 12 months), chronic gouty arthritis, tophi, renal impairment (eGFR <60), patients on diuretics and primary gout at an early age.

c)Aim of urate lowering to reduce serum urate to $<300 \mu \mathrm{mol} / /$. (2) Methods: Inclusion criteria:

All patients being treated for gout in the department of rheumatology, between $1^{\text {st }}$ October 2016 to $31^{\text {st }}$ September 2017, were included in this retrospective study. Demographics, treatment details obtained from electronic patient records. Adherence to the BSR guidelines was expressed as percentage. 